\section{Subcellular localization and distribution of the reduced folate carrier in normal rat tissues}

\author{
M. Hinken, ${ }^{1}$ S. Halwachs, ${ }^{1}$ C. Kneuer, ${ }^{2}$ \\ W. Honscha ${ }^{1}$ \\ ${ }^{1}$ Institute of Pharmacology, Pharmacy \\ and Toxicology, Faculty of Veterinary \\ Medicine, University of Leipzig, Germany; \\ 2Federal Institute for Risk Assessment, \\ Department of Chemical Safety, Berlin, \\ Germany
}

\section{Abstract}

The Reduced folate carrier (Rfc1; Slc19a1) mediated transport of reduced folates and antifolate drugs such as methotrexate (MTX) play an essential role in physiological folate homeostasis and MTX cancer chemotherapy. As no systematic reports are as yet available correlating $\mathrm{Rfcl}$ gene expression and protein levels in all tissues crucial for folate and antifolate uptake, storage or elimination, we investigated gene and protein expression of rat $\mathrm{Rfcl}$ ( $\mathrm{rRfcl}$ ) in selected tissues. This included the generation of a specific anti-rRfc1 antibody. Rabbits were immunised with isolated rRfcl peptides producing specific anti-rRfcl antiserum targeted to the intracellular C-terminus of the carrier. Using RT-PCR analysis, high rRfcl transcript levels were detected in colon, kidney, brain, thymus, and spleen. Moderate rRfcl gene expression was observed in small intestine, liver, bone marrow, lung, and testes whereas transcript levels were negligible in heart, skeletal muscle or leukocytes. Immunohistochemical analyses revealed strong carrier expression in the apical membrane of tunica mucosa epithelial cells of small intestine and colon, in the brush-border membrane of choroid plexus epithelial cells or in endothelial cells of small vessels in brain and heart. Additionally, high rRfcl protein levels were localized in the basolateral membrane of renal tubular epithelial cells, in the plasma membrane of periportal hepatocytes, and sertoli cells of the testes. Taken together, our results demonstrated that $\mathrm{rRfcl}$ is expressed almost ubiquitously but to very different levels. The predominant tissue distribution supports the essential role of Rfc1 in physiological folate homeostasis. Moreover, our results may contribute to understand antifolate pharmacokinetics and selected organ toxicity associated with MTX chemotherapy.

\section{Introduction}

Reduced folate coenzymes like N5-methyltetrahydrofolate are essential cofactors required for the transfer of one-carbon units in the biosynthesis of purines and pyrimidines as well as in methylation reactions including the formation of methionine from homocysteine. ${ }^{1}$ The importance of folate coenzymes is evidenced by the many clinical diseases associated with folate deficiency, such as neural tube defects in neonates, cardiovascular complications, megaloblastic anaemia and carcinogenesis. ${ }^{1,2}$ As mammalian cells do not possess the ability to synthesize folate derivatives de novo, folate intake from dietary sources is vitally required for normal cell growth and differentiation. $^{3}$

The chemotherapeutic drug methotrexate (MTX, Amethopterin) is a competitive inhibitor of the folate-dependent enzyme dihydrofolate reductase resulting in inhibition of DNA synthesis and cell death. ${ }^{4}$ MTX represents an essential component in the treatment of malignancies including leukemia, lymphoma or head and neck cancers, ${ }^{4,5}$ as well as autoimmune diseases such as rheumatoid arthritis. ${ }^{6}$

The Reduced Folate Carrier/Reduced folate carrier (RFC1/Rfc1; SLC19A1/Slc19a1) provides the major route for cellular uptake of natural folate compounds and antifolate drugs including MTX into liver, kidneys and other tissues. ${ }^{5,7-9}$ Both human $\mathrm{RFCl}^{10}$ and rodent $\mathrm{RfCl}^{7,11-13}$ cDNA clones have been isolated and encode a carrier protein with 12 putative transmembrane domains (TMDs). Several studies confirm that Rfcl provides a low capacity but high affinity transport system for reduced folates and MTX. ${ }^{5,14,15}$ As to the functional properties of this carrier, we $\mathrm{e}^{14,16}$ and other researchers ${ }^{17-19}$ have shown that at acidic $\mathrm{pH}$, human RFC1 and Rfcl from rat (rRfc1) are working mainly as folate transporters with no obvious sodium-dependency, whereas at neutral pH both carriers mediate uptake of MTX in a clearly sodium-dependent and folic acidinsensitive manner. It has therefore been concluded that human RFCl and rRfcl are orthologs. ${ }^{16}$ Additionally, the mRNA variant Rfc2 resulting from alternative splicing has been previously described. ${ }^{7,20}$ The Rfc 2 protein was predicted to contain 7 TMDs. ${ }^{20}$

Despite the substantial role of this carrier in folate homeostasis and MTX cancer chemotherapy, comparatively little information is as yet available on the distribution and subcellular localisation of RFC1/Rfc1 in mammalian tissues. Previous gene expression studies demonstrated that RFC1 transcripts are expressed ubiquitously but to different levels in all tissues and a number of tumour cells. ${ }^{5,13}$ Rfcl protein expression was only
Correspondence: Dr. Sandra Halwachs, Institute of Pharmacology, Pharmacy and Toxicology, Faculty of Veterinary Medicine, An den Tierkliniken 15, Universität Leipzig, 04103 Leipzig, Germany.

Tel. +49.341.9738142 - Fax: +49.341.9738149.

E-mail: halwachs@vetmed.uni-leipzig.de

Key words: reduced folate carrier, folate homeostasis, methotrexate, cancer, chemotherapy, immunohistochemistry.

Contributions: $\mathrm{MH}$ performed the gene expression studies as well as the generation of rRfcl specific antiserum including immunohistochemical experiments; SH participated in the immunization of rabbits and prepared the manuscript; CK and WH participated in the design and coordination of this study; WH additionally advised the preparation of the manuscript.

Acknowledgements: the authors would like to thank H.-A. Schoon and M. Wipplinger (University of Leipzig, Germany) for providing support in immunohistochemical staining.

Conflict of interest: the authors declare no potential conflict of interest.

Received for publication: 10 November 2010 . Accepted for publication: 13 December 2010.

This work is licensed under a Creative Commons Attribution 3.0 License (by-nc 3.0).

(C) Copyright M. Hinken et al., 2011

Licensee PAGEPress, Italy

European Journal of Histochemistry 2011; 55:e3 doi:10.4081/ejh.2011.e3

assessed in selected murine tissues such as small intestine. ${ }^{21}$ Moreover, there is only limited data on the subcellular distribution of this carrier protein. Murine Rfcl (mRfcl) was detected in the apical membrane of small intestine and colon as well as choroid plexus and retina pigment epithelium.22 Additionally, mRfcl was localized to the basolateral surface of renal tubular epithelial cells. ${ }^{21}$ Furthermore, Rfc was detected in hepatocellular plasma membrane as well as in jejunal and kidney brush border membrane vesicles from micropigs. ${ }^{23}$ However, comparable studies to the immunohistochemical determination of hRFC1 or rRfcl are not available. Moreover, there are currently no systematic reports correlating $\mathrm{Rfcl}$ gene and protein expression in all tissues of particular relevance for folate and antifolate uptake, storage and elimination. Particularly, the expression of Rfcl protein from rat (rRFC1), a common animal model for man, by immunological methods has not been described up to now. Therefore, the aim of this study was to systematically investigate rRFC1 gene expression and protein levels and in 
selected rat tissues. Here, the determination of subcellular carrier localization was of particular interest in order to improve the understanding of the role of rRfcl in the vectorial transport of folate analogues across cell plasma membranes.

\section{Materials and Methods}

\section{Reagents}

All chemicals including media and supplements were obtained from Sigma-Aldrich (Deisenhofen, Germany) unless otherwise stated.

\section{Cell culture and tissues}

Madin-Darby canine kidney (MDCK) type II cells stably expressing rRfcl tagged with a Cterminal HA epitope (MDCK-rRfc1-HA) were generated as previously described. ${ }^{8}$ MDCKrRfc1-HA and wild-type MDCK II cells were maintained in Earle's modified Eagle's medium (MEM; PAA, Coelbe, Germany) containing $10 \%(\mathrm{v} / \mathrm{v})$ fetal calf serum (Gibco, Karlsruhe, Germany) and $1 \mathrm{X}$ non-essential amino acids as previously delineated. ${ }^{8}$

Selected tissues were obtained from male Sprague-Dawley rats (300 g). Animals were euthanized by asphyxiation with $\mathrm{CO}_{2}$ and selected organs were removed. All tissues were snap frozen in liquid nitrogen and subsequently stored at $-80^{\circ} \mathrm{C}$. These procedures were conducted in the central animal facility of the Medical Faculty of the University of Leipzig, according to institutional guidelines for ethical care and use of animals for experimental and other scientific purposes.

\section{Construction of fusion proteins and production of rRfc1 specific peptides}

The predicted structure of the rRfcl protein has been previously described. ${ }^{7}$ Highly antigenic regions in the rRfcl protein sequence were identified by determination of the antigenic index ${ }^{24}$ using Protean 5.06 (DNAStar software, Inc., Madison, WI, USA). The selected $\mathrm{rRfcl}$ peptide sequence at amino acid residues 445-512 comprising the intracellular C-terminus of the carrier was amplified by PCR using 1/50 of cDNA (pRK-MTX1) that has been previously described. ${ }^{8}$ The PCR product denoted intracellular domain 7 (ID7) was cloned into the expression vector pET-41a (Novagen, Inc., Madison, WI, USA) via EcoRI/HindIII (NEB, Ipswich, MA, USA). The pET-41a vector contains a glutathione-S-transferase (gst) and histidine (His) ${ }_{6}$ gene as fusion tags to aid in purification steps. The resulting pET-ID7 vector was confirmed by sequencing and restriction analysis, respectively. After expression of the pET-ID7 fusion protein in IPTG (0.4 mM; Roth, Karlsruhe, Germany)induced $E$. coli Rosetta cells (Novagen) the bacteria were lysed with $20 \mathrm{mg} / \mathrm{g}$ lysozyme including DNase (250 U/g). Affinity purification of soluble His6-tagged pET-ID7 fusion proteins was performed using Ni-NTA His-Bind ${ }^{\circledR}$ Resin (Novagen). Subsequently, fusion proteins were eluted with imidazole $(300 \mathrm{mM})$ in elution buffer $(0.5 \mathrm{M} \mathrm{NaCl}, 20 \mathrm{mM}$ Tris- $\mathrm{HCl}, \mathrm{pH}$ 7.9). The purity of protein was assessed by SDS-PAGE (16\%) and Coomassie staining (Coomassie Brilliant Blue R-250, Roth, Karlsruhe, Germany). The amount of pET-ID7 protein was determined by saturation of a HisBind $^{\circledR}$ Column (Novagen) with a theoretical capacity of $20 \mathrm{mg}$ protein. Then, GST- and Histags were cleaved from the rRfcl specific peptide (RSP) by means of enterokinase (30 $\mu \mathrm{g} / \mathrm{mg}$ fusion protein) over $6 \mathrm{~h}$ in dialysis buffer $(200 \mathrm{mM} \mathrm{NaCl}, 20 \mathrm{mM}$ Tris-HCl, $200 \mathrm{mM}$ imidazole pH 8.0). To obtain RSP as the pure antigen, samples were filtrated $(3000 \times \mathrm{g})$ for $2 \mathrm{~h}$ through centrifugal concentrators (Centriplus YM-50, Millipore, Schwalbach, Germany). Concentrated RSP was stored at $4^{\circ} \mathrm{C}$ until immunization.

\section{Immunization and generation of polyclonal Rfc1 antiserum}

In this study, three New Zealand White rabbits (1800-2000 g, Charles River laboratories, Ki $\beta$ legg, Germany) were immunised with RSP ID7 to obtain specific polyclonal Rfcl antiserum. Animals were housed under standard conditions in the central animal facility of the Medical Faculty of the University of Leipzig according to institutional guidelines for ethical care and use of animals for experimental and other scientific purposes.

The RSP ID7 (0.4-1 mg/mL) was emulsified with an equal volume of Freund's adjuvant, and $1 \mathrm{~mL}$ containing $0.2-0.5 \mathrm{mg}$ ID7 was injected into 10 dorsal sites of rabbits. Animals received a booster injection with $0.2-0.5 \mathrm{mg}$ ID7 emulsified in Freund's incomplete adjuvant after 2, 4, 6 , and 8 weeks after primary immunization. Rabbits were bled before primary immunization (preimmune) as well as 4, 6, and 8 weeks after immunization. Subsequently, affinity purification of ID7 antibody was performed using CRBr - activated agarose. Initially, a column exhibiting bound control vector pET-41 was used to remove unspecific antibodies against fusion protein without $\mathrm{rRfc}$. In a second purification step, ID7 antiserum was concentrated using a column to which the corresponding antigen pET-ID7 was covalently linked. Elution of purified antiserum was achieved using neutralisation buffer (1 M Tris-HCl, pH 9). Purified and concentrated ID7 antiserum was stored at $4^{\circ} \mathrm{C}$ after addition of NaN3 (10 mM).

\section{RT-PCR}

Selected tissues were obtained from male Sprague-Dawley (SD) rats of approximately $300 \mathrm{~g}$ weight. Total RNA was prepared from 20 mg of liver, kidney, spleen, and thymus or 30 mg of other selected tissues using the RNeasy Mini system (Qiagen, Hilden, Germany). Purification of total RNA was achieved by digestion with DNase (15 U; Qiagen, Hilden, Germany). Contamination with contractile proteins of RNA samples from skeletal or cardiac muscle fibres were removed by incubation with proteinase $\mathrm{k}$ for $10 \mathrm{~min}\left(55^{\circ} \mathrm{C}\right)$. Reverse transcription into cDNA using $1 \mu \mathrm{g}$ total RNA was performed under standard conditions employing the Omniscricpt RT kit (Qiagen) with $4 \mathrm{U}$ of reverse transcriptase and $1 \mu \mathrm{M}$ oligo $\left(\mathrm{dT}_{16^{-}}\right)$primer (MWG Biotech, Ebersberg, Germany). Semiquantitative PCR of $1 \mu \mathrm{L}$ cDNA was carried out using the PCRMaster-Mix S (Peqlab, Erlangen, Germany) with $1.25 \mathrm{U}$ taq-DNA-polymerase, $0.25 \mathrm{mM}$ dNTPs, 0.4 pmol of rRfc1 specific sense (5'CCAGAGCCCAGGAAACTG-3') and antisense (5'-GCAATCTGAAAAGTGGCAATG-3') primers or specific $\beta$-actin primers as previously delineated. ${ }^{25}$ PCR amplification was performed over 40 cycles for rRfcl and 30 cycles for $\beta$-actin with an initial denaturation step of $30 \mathrm{sec}$ at $94^{\circ} \mathrm{C}$ followed by annealing and extension for $30 \mathrm{sec}$ at $58^{\circ} \mathrm{C}$ and $72^{\circ} \mathrm{C}$, respectively, A final extension was carried out at $72^{\circ} \mathrm{C}$ for $3 \mathrm{~min}$. The PCR products were analysed by agarose gel electrophoresis with regard to size of the expected fragment. $§$ actin was used as positive control and amplification of genomic DNA was excluded by omitting reverse transcriptase.

\section{SDS-PAGE and immunoblotting}

MDCK II cells expressing rRfc1-HA or wildtype MDCK II cells were cultured until subconfluency. Cells $\left(15 \times 10^{6}\right)$ were washed with icecold PBS und incubated in Laemmli lysis buffer $^{26}$ without $\beta$-mercaptoethanol. Proteins were separated on SDS/10\% polyacrylamide gel and blotted onto polyvinylidene fluoride (PVDF) membrane. Unspecific binding was blocked with $3 \%$ BSA in TBS-Tween $(20 \mathrm{mM}$ Tris-HCl, pH 7.5, $150 \mathrm{mM} \mathrm{NaCl}, 0.05 \%$ (v/v) Tween 20$)$ overnight $\left(4^{\circ} \mathrm{C}\right)$. Membranes were probed with rabbit anti rRfc1 antiserum (ID7; 1:500) for $1 \mathrm{~h} \mathrm{(rt)} \mathrm{following} \mathrm{visualization} \mathrm{with}$ AP-conjugated goat anti-rabbit IgG (1:2000, Dako Cytomation, Hamburg, Germany). Protein samples of native HPCT-1E3 cells probed with anti- rRfcl antiserum served as a negative control.

\section{Immunofluorescence}

For indirect immunolocalization of $\mathrm{rRfcl}$, 
MDCK-rRfc1-HA cells were cultured on glass cover slips. Cells were fixed with $2 \%$ (w/v) paraformaldehyde $\left(10 \mathrm{~min}\right.$ at $20^{\circ} \mathrm{C}$ ) and permeabilised with $0.1 \%(\mathrm{v} / \mathrm{v})$ Triton X-100. Unspecific binding was blocked with $3 \%(\mathrm{v} / \mathrm{v})$ BSA in phosphate-buffered saline (PBS). Nuclear staining was achieved by addition of DAPI $(0.5 \mu \mathrm{g} / \mathrm{mL})$. Cells were incubated with rabbit anti rRfc1 antiserum (ID7; $1: 500)$ at $4{ }^{\circ} \mathrm{C}$ overnight in $3 \%(\mathrm{v} / \mathrm{v})$ BSA in PBS. Visualisation of rRfcl was achieved with FITC-conjugated anti-rabbit IgG (1:200) for $1 \mathrm{~h}$ at room temperature. Finally, the specimens were washed and mounted on slides. As a positive control, rRfcl-HA was detected with mouse monoclonal anti-HA antibody (HA-7; 1:200) overnight at $4^{\circ} \mathrm{C}$ following visualization with $\mathrm{R}$ PE-conjugated goat anti-mouse IgG (1:200; Dako Cytomation, Hamburg, Germany) for $1 \mathrm{~h}$ at room temperature. Control experiments were performed using wild-type MDCK II cells as well as incubation of cells with rRfcl antiserum in the presence of pET-ID7 fusion protein $(5 \mu \mathrm{g} / \mathrm{mL})$. Cells were viewed with a fluorescence microscope (Olympus BX50, Hamburg, Germany).

\section{Immunohistochemistry}

Selected organs were obtained from 2 male Sprague-Dawley (SD) rats of approx. $300 \mathrm{~g}$ weight. Cryostat sections $(5-7 \mu \mathrm{m})$ were cut and fixed in actone $\left(-20^{\circ} \mathrm{C}\right)$ for $10 \mathrm{~min}$. Then, cryosections were dried at room temperature (rt) for $10 \mathrm{~min}$ and washed in PBS for $15 \mathrm{~min}$. Immunohistochemistry on cryosections was performed using a modified method previously described. ${ }^{21}$ In brief, endogenous peroxidase activity was quenched by incubation of slides into cold $0.03 \% \mathrm{H}_{2} \mathrm{O}_{2}$ on ice for $15 \mathrm{~min}$. Nonspecific binding was blocked with $3 \%(\mathrm{v} / \mathrm{v})$ BSA in PBS for $1 \mathrm{~h}$ (rt). Specific rRfc1 antiserum was added at a 1:500 dilution for $72 \mathrm{~h}$ at $4^{\circ} \mathrm{C}$. Then, samples were rinsed 3 times with PBS buffer for $10 \mathrm{~min}$ and incubated with HRP-conjugated swine anti-rabbit secondary antibody (1:250; Dako Cytomation, Hamburg, Germany) in blocking buffer overnight $\left(4^{\circ} \mathrm{C}\right)$. Afterwards, 3,3'- diaminobenzidine (DAB) substrate solution (1:50; Dako Cytomation, Hamburg, Germany) was added for $10 \mathrm{~min}$. Then, the reaction was stopped by several washing steps with PBS, samples were counterstained with Mayer's hematoxylin and mounted in Fluor Save reagent (Calbiochem, Bad Soden, Germany). Control experiments were carried out by incubation of samples with the preimmune serum.

\section{Results}

\section{Generation of rRfc1 specific pep- tides for immunization}

The structure of the $\mathrm{rRfc} 1$ protein with 12 predicted transmembrane domains has been previously described. ${ }^{7}$ For the development of specific antiserum directed against certain peptide sequences of Rfcl, highly antigenic regions were selected simultaneously comprising intra- or extracellular loops of the carrier protein (Figure 1A) facilitating the use of the antiserum for immunohistochemical studies. Several antigenic peptide sequences within the rRfc1 protein were identified by determination of the antigenic index (AI) (Figure 1B) illustrated as positive values for certain protein subdomains $(\mathrm{AI}>0)$. Highly antigenic regions with an $\mathrm{AI}$ of $\geq 1.5$ were calculated for intracellular localized amino acid residues 127 denoted as ID1, 200-268 (ID4), 445-512 (ID7) as well as extracellular localized amino acid residues 40-73 designated OD1 and amino acid residues 403-428 (OD6) (Figure 1 A,B) indicating a high antigenicity.

Nucleotide sequences encoding these peptide domains were amplified and cloned into the expression vector pET-41a exhibiting a His $_{6}$-tag to aid in purification steps resulting in the following fusion proteins: pET-ID1, pETID4, pET-ID7 as well as pET-OD1 and pET-OD6. As expected, fusion protein pET-ID7 exhibited a molecular weight of $41.9 \mathrm{kDa}$ (Figure $2 \mathrm{~A}$, left column). After cleavage of vector-associated tags with proteinase $\mathrm{K}$ the specific $\mathrm{rRfcl}$ ID7 peptide (10.5 kDa) comprising the intracellular C-terminus of the carrier was obtained (Figure 2A, right column). Cleavage of other selected fusion proteins resulted in the production of the following rRfcl peptides: ID1 (6,2 kDa), ID4 (11 kDa), and OD1 (7.0 kDa) (not shown).

\section{Antigen reactivity and specificity of rRfc1 antiserum}

In order to produce specific rRfcl antiserum, rabbits were immunized by standard procedures with the above mentioned rRfc1 selective peptides. Specificity of the respective antiserum was confirmed in MDCK cells stably expressing $\mathrm{rRfc} 1 .^{8}$

Using Western blot analysis, a single strong band was detected with ID7 antiserum at $\sim 72$ $\mathrm{kDa}$ (Figure $2 \mathrm{~B}$ ) representing $\mathrm{rRfc} 1 .^{7}$ In contrast, no band could be observed in wild-type MDCK cells lacking rRfcl expression, indicating that this antiserum was specific for rRfcl. Moreover, Western blot analyses of MDCK-rRfc1HA cells using anti-HA antibody equally produced a band at $\sim 72 \mathrm{kDa}$ (not shown), validating
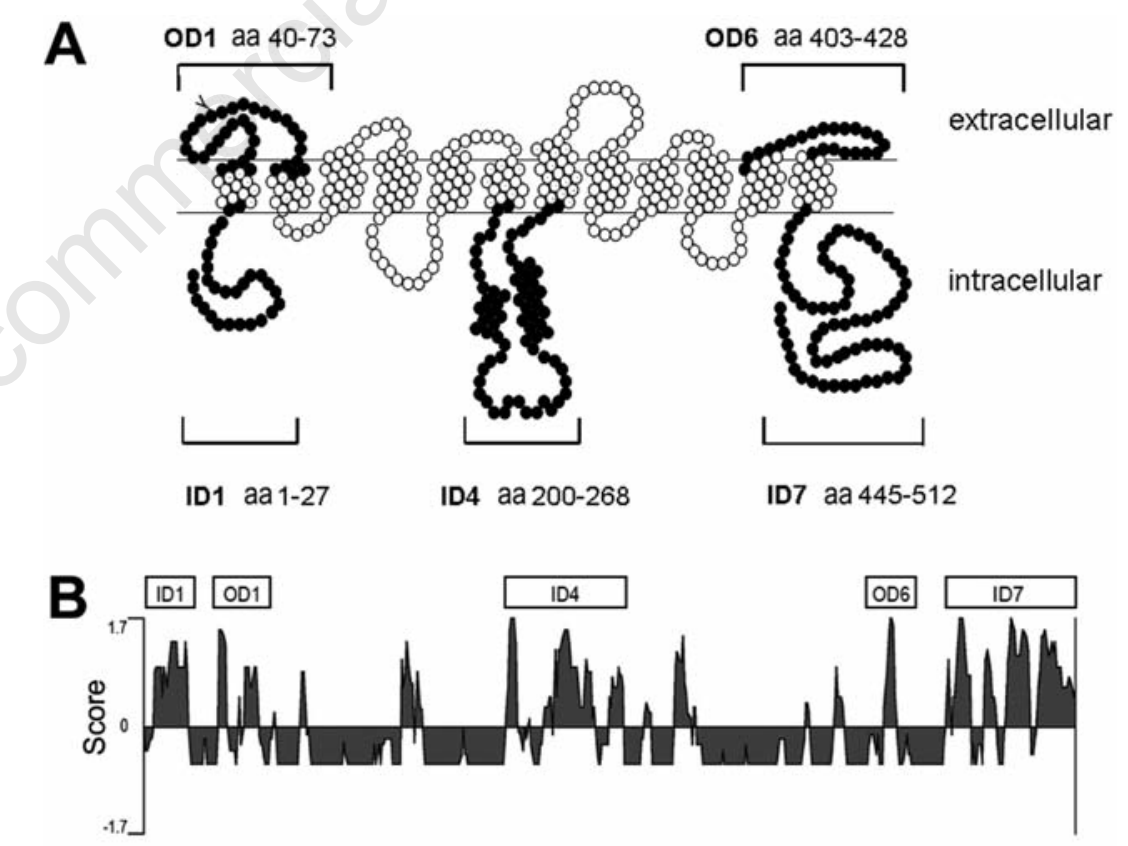

Residue

Figure 1. Determination of antigenic regions in the $\mathrm{rRf} 1$ protein sequence. $A$, the structure of the $\mathrm{rRfcl}$ protein with 12 predicted transmembrane domains was used to select adequate protein domains for immunization. Suitable protein sequences are highlighted in black comprising intracellular domains or extracellular localized domains. B, highly antigenic regions in the $r R f c 1$ protein sequence were identified by determination of the antigenic index by Jameson-Wolf. The highly antigenic domain corresponding to amino acid (aa) residues 445-512 comprising the intracellular C-terminus of the carrier (ID7) was used to generate the polyclonal antiserum. 
the specificity of ID7 antiserum for rRfcl.

To further corroborate the specificity of rabbit rRfc1 ID7 antiserum, cells were simultaneously probed with ID7 antiserum and anti-HA antibody and analysed by indirect immunofluorescence. Incubation with ID7 antiserum (Figure $3 \mathrm{~A}$ ) and anti-HA antibody (Figure $3 \mathrm{~B}$ ) resulted in a strong immunopositive signal localized to the plasma membrane of MDCKrRfc1-HA cells. Overlay of both pictures revealed, that subcellular localization of both staining was identical (Figure $3 \mathrm{C}$ ). In contrast, no staining was detected in wild-type MDCK cells (Figure 3 D). Moreover, the ID7-associated immunopositive signal was abolished by concurrent incubation of MDCK-rRfc1-HA cells with pET-ID7 fusion protein further approving selectivity of the ID7 antibody (Figure $3 \mathrm{E}$ ). In regard to the other selected rRfcl peptides no specific carrier signal could be detected in Western blot or immunocytochemical studies using MDCK-rRfc1-HA cells (not shown).

\section{Gene expression of rRfc1}

To determine gene expression of $\mathrm{rRfcl}$ in normal rat tissues, we performed a RT-PCR analysis and compared the expression profile of selected organs. In this study, rRfc specific primers were used that also allow the detection of the rRfc splicing variant rRfc $2 .^{20}$ As shown in Figure 4, rRfc1 transcripts were detected in all chosen organs. As to the carrier expression in intestine, our results show higher levels of rRfcl mRNA in colon than in small intestine. Moreover, there was a significant decrease in carrier expression levels from proximal duodenum to distal ileum within the small intestine. Besides colon, a strong rRfcl expression was observed in kidney, brain, thymus, and spleen. A moderate signal was obtained for liver, lung, duodenum, jejunum, testis, and bone marrow. In contrast, rRfc1 transcript levels in arteries as well as in skeletal or cardiac muscle fibres were near the detection limit. In a number of tissues including kidney, brain, thymus, and spleen as well as duodenum, colon and testis expression of the rRfc splicing variant rRfc2 could also be observed (Figure 4). With regard to the other selected tissues exhibiting a moderate to weak rRfc1 expression, no rRfc2 transcripts were detected may be due to the detection limit.

\section{Tissue distribution and subcellular localization of $\mathrm{rRfc} 1$ protein}

In order to compare rRfcl transcript levels and tissue expression with the distribution pattern of Rfc1 protein, carrier localization was investigated in selected rat tissues using specific anti-Rfc1 ID7 antiserum.

In a variety of normal rat tissues, strong immunoreactivity was observed. Prominent staining was recovered in the gastrointestinal
A

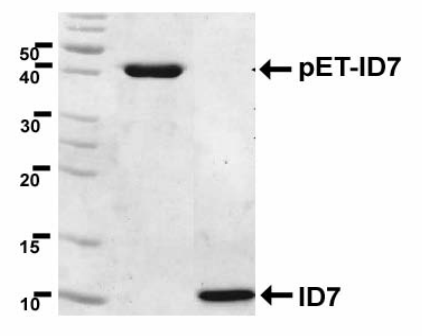

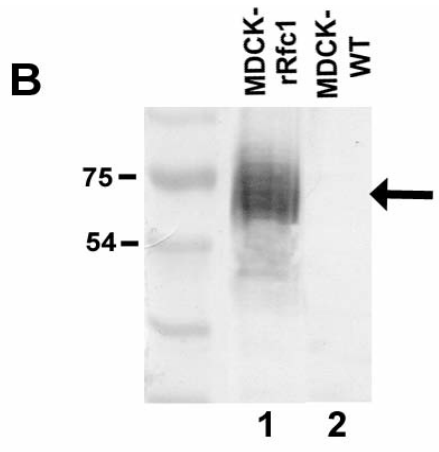

Figure 2. SDS-PAGE analysis of Rfc1 specific peptide (RSP) ID7. A, Equal protein amounts of pET-ID7 fusion protein $(-42 \mathrm{kDa})$ or isolated RSP ID7 $(-10.5 \mathrm{kDa})$ were separated on a SDS/16\% polyacrylamide gel and proteins were detected by Coomassie blue staining. B, Specificity of ID7 antiserum against the C-terminus of $\mathrm{Rfcl}$ from rat by Western blot analysis. Equal protein amounts of MDCK-rRfc1-HA (lane 1) or wild-type MDCK II (lane 2) cells were separated on a SDS $/ 10 \%$ polyacrylamide gel. Rfc1 was detected by ID7 antibody and is apparent at $\sim 72 \mathrm{kDa}(\rightarrow)$.
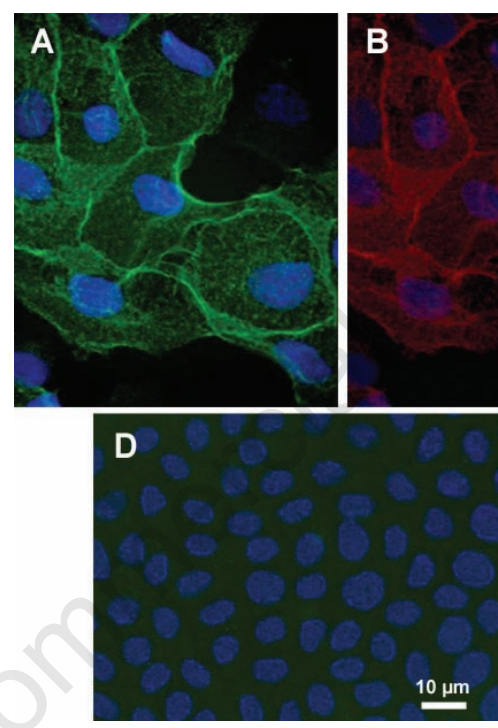
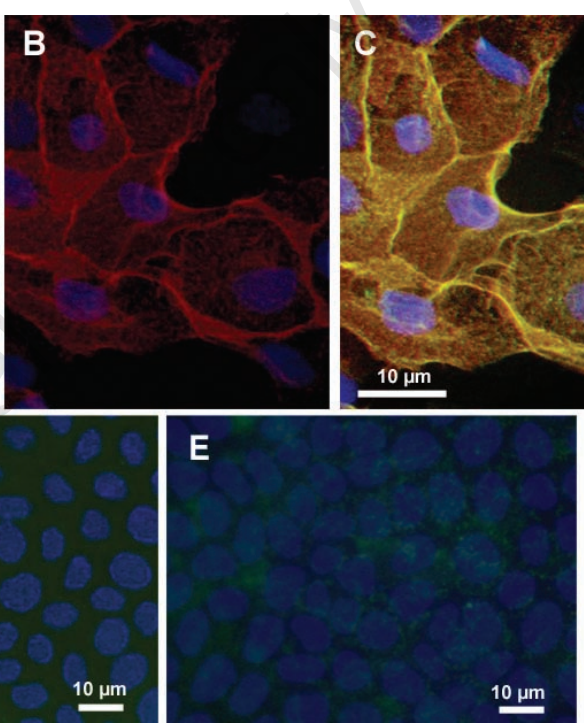

Figure 3. Specificity of ID7 antiserum against the C-terminus of $\mathrm{Rfcl}$ from rat by indirect immunofluorescence. MDCK-rRfc1-HA (A-C, E) or wild-type MDCK II cells (D) were seeded on glass cover slips and cells were incubated with rabbit anti $\mathrm{rRfcl}$ antiserum (ID7; 1:500) in the presence (E) or absence of pET-ID7 fusion protein $(5 \mu \mathrm{g} / \mathrm{mL})$ or with a specific anti-HA antibody (1:200, B). Colocalization of $\mathrm{Rfcl}$ and $\mathrm{Rfc1}-\mathrm{HA}$ protein results in simultaneous fluorescence producing a yellow/orange signal (C). Cell nuclei (blue) were visualized by means of DAPI (A, Rfcl in green; B, Rfc1-HA in red; Magnification A-C, $\times$ 100; D+E, ×40).

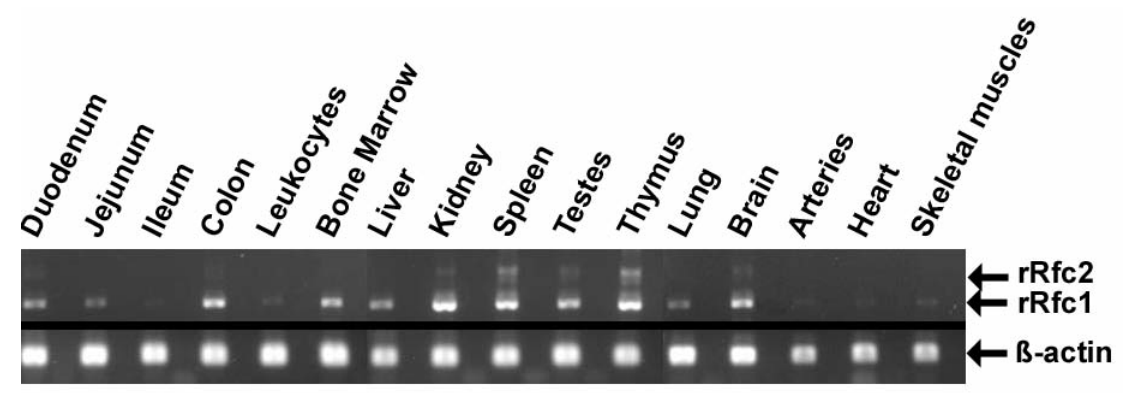

Figure 4. $\mathrm{Rfc1}$ gene expression in selected rat tissues as assessed by RT-PCR analysis. Total RNA was isolated from selected organs and used for RT-PCR analysis as described in the Materials and Methods section. Sizes of expected Rfc1 (443 bp) or Rfc2 (645) transcripts are indicated by arrows. RT-PCR of $\beta$-actin $(138 \mathrm{bp})$ was carried out as positive control. The RT-PCR analysis shown is representative of two independent experiments. 
tract, with a strong immunopositive signal in duodenum and colon (Figure $5 \mathrm{~A}$ ) while staining levels were moderate in jejunum (Figure 5 B) and ileum (not shown). In kidney, high levels of immunohistochemical staining were detected in proximal and distal tubular epithelial cells (Figure $5 \mathrm{C}$ ) whereas no signal was recovered in the gomeruli (not shown) or the collecting duct (Figure $5 \mathrm{C}$ ). Moderate staining for Rfc1 was observed in liver (Figure $5 \mathrm{D}$ ). Here, Rfc1 immunoreactivity was particularly determined in the periportal zone of hepatic lobules located near the portal triade. In contrast, no carrier signal was detected in the centrilobular zone around the central lobular vein. Treatment of brain tissues with anti-Rfc1 ID7 antiserum resulted in a strong staining in choroid plexus epithelial cells (Figure $6 \mathrm{~A}$ ). Additionally, Rfc1 immunoreactivity was observed in capillary endothelial cells, which represent the blood-brain barrier (Figure 6 B) and cells composing the pia mater (not shown). In regard to skeletal muscle, positive Rfcl signals were only present in the perimysium likely associated with small blood vessels (Figure $6 \mathrm{C}$ ). Similarly, heart tissue probed with Rfc1 antiserum only showed a positive signal in endothelial cells of small vessels (Figure 6 D). In skeletal or cardiac muscle cells, no staining was observed. Additionally, no specific Rfcl immunoreactivity could be established in lung, i.e., alveolar epithelial cells, bronchus associated lymphoid tissue (BALT) associated cells (not shown). Furthermore, significant staining could not be observed in leukocytes or bone marrow (not shown). In general, no immunoreactivity was detected in samples probed with preimmune serum (not shown).

Using immunohistochemical analyses, we further aimed at determining the subcellular localization of rRfcl protein in selected normal rat tissues. In the gastrointestinal tract, rRfcl immunoreactivity was observed in the apical membrane of jejunum (Figure 5 B). Moreover, our results indicate subcellular localization of Rfcl at the apical membrane of colon (Figure 5 A). Additionally, rRfc1 was detected on the brush-border membrane of choroid plexus epithelial cells facing the cerebrospinal fluid while no positive signal was recovered in the basolateral membrane adjacent to brain capillaries (Figure $6 \mathrm{~A}$ ). High levels of Rfc1 protein were also found in the apical membrane of endothelial cells of small vessels in heart tissue (Figure 6 D). Similarly, our results indicate subcellular localization of Rfcl at the apical membrane of endothelial cells composing the blood-brain barrier (Figure 6 B) as well as of small vessels in skeletal muscle tissue (Figure 6C). In contrast, Rfcl was observed in the basolateral membrane of renal tubular epithelial cells while no immunoreactivity was
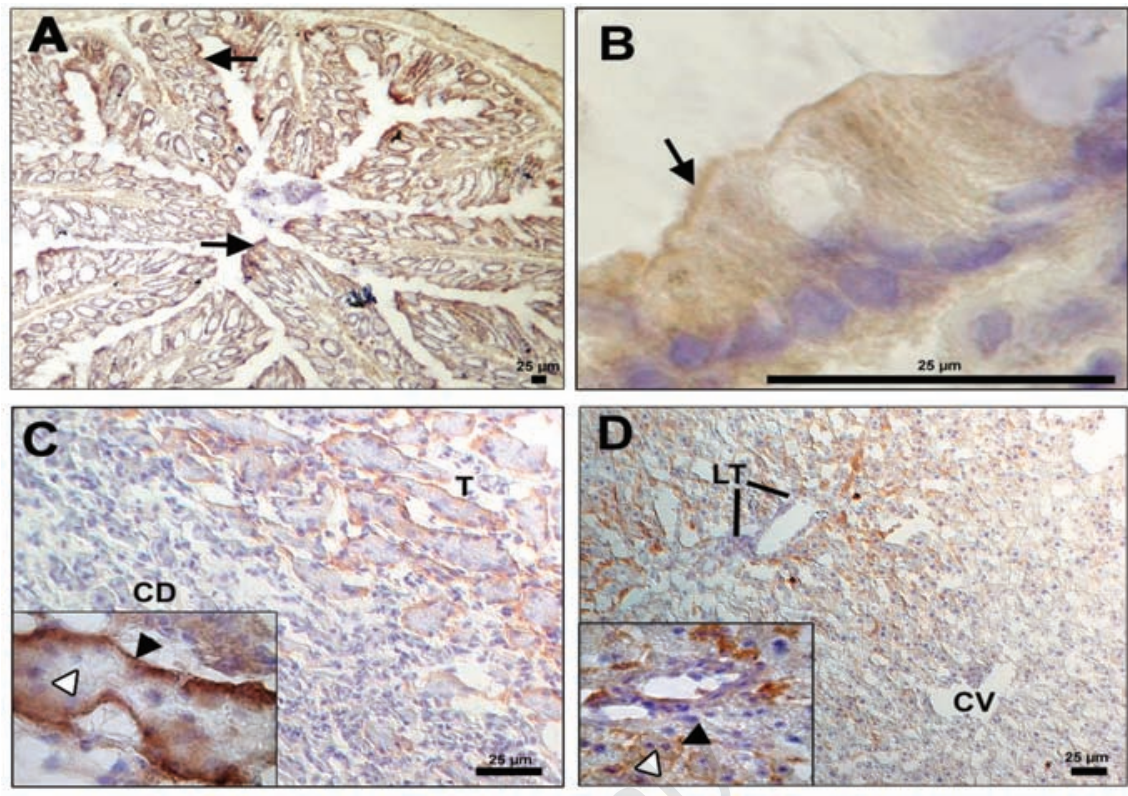

Figure 5. Immunolocalization of $\mathrm{Rfc1}$ in rat tissues by specific anti $\mathrm{Rfc1}$ ID7 antiserum. $\mathrm{A}, \mathrm{Rfc1}$ immunoreactivity was detected in tunica mucosa cells (arrow) of colon $(4 \times)$ and $\mathrm{B}$, at the apical membrane (arrow) of jejunal epithelial cells $(100 \times)$. C, expression of $\mathrm{Rfc1}$ in the basolateral membrane of renal tubule cells $(20 \times)$, not collecting duct; insert, renal tubule, $(100 \times)$. D, in liver Rfc1 was particularly found in the plasma membrane of hepatocytes in the periportal zone of hepatic lobules located near the portal triade, not the centrilobular zone (10x); insert, $\mathrm{Rfcl}$ was localized to the basolateral membrane (black arrowhead) while the amount of $\mathrm{Rfcl}$ in the apical membrane (white arrowhead) was negligible, $(100 \times) . C D$, collecting duct; $T$, renal tubule; CV, central vein; $L T$, liver triade.
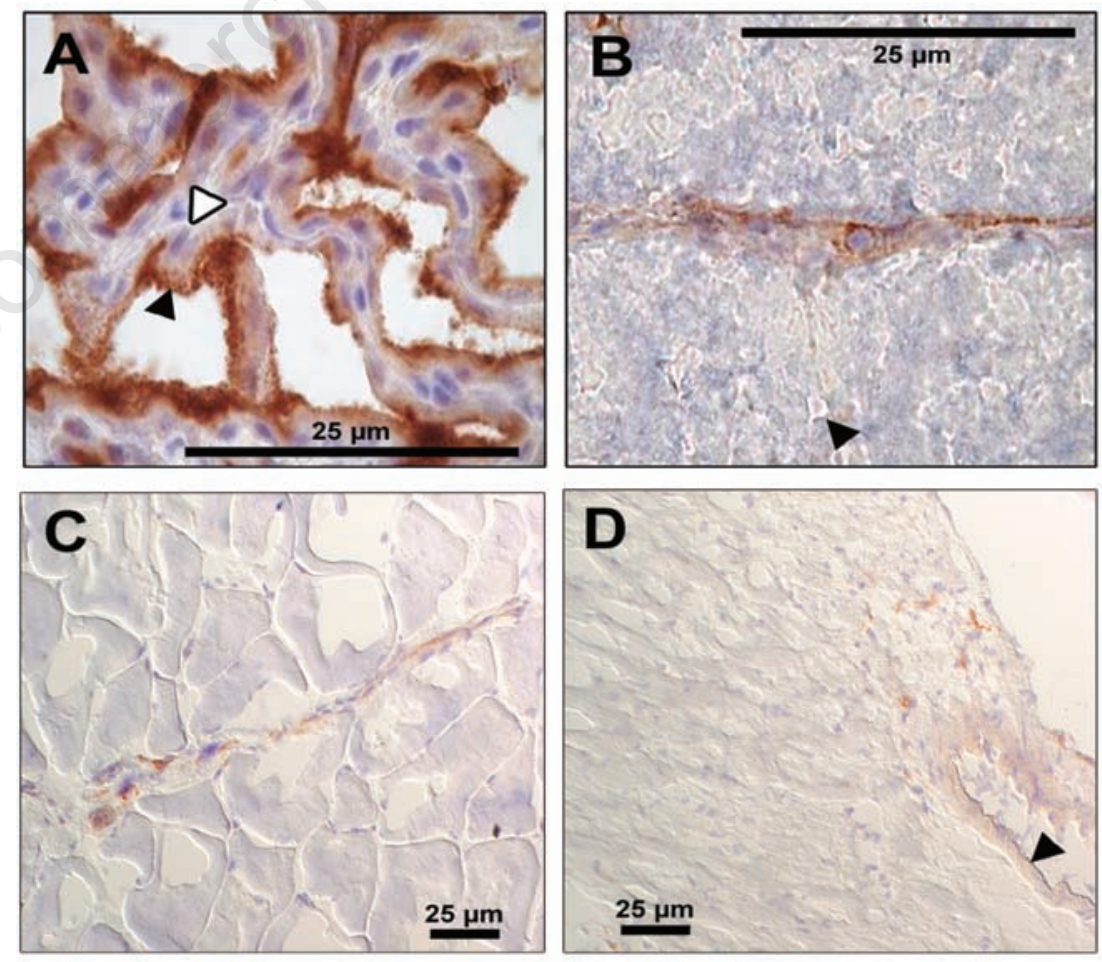

Figure 6. Immunohistochemical analysis of rat tissues exposed to specific anti Rfc1 ID7 antiserum. A, choroid plexus, $\mathrm{Rfcl}$ is localized at the apical membrane of choroid plexus epithelial cells (black arrowhead) not at the basolateral membrane (white arrowhead) $(100 \times)$. B, Rfc1 immunoreactivity in endothelial cells of small brain vessels, not pyramid cells (black arrowhead) $(100 \times)$. C. positive $\mathrm{Rfcl}$ signals were present in the perimysium of skeletal muscle fibres $(20 \times)$. D, heart, $R f c 1$ localized to the apical membrane of endothelial cells of small vessels (black arrowhead), not cardiac muscle cells $(20 \times)$. 
apparent in the apical membrane or in the cytosol (Figure 5C). Moreover, cellular distribution of Rfc1 was predominantly apparent at the basolateral plasma membrane of periportal hepatocytes while no cellular staining was determined in hepatocytes of the centrilobular zone (Figure $5 \mathrm{D}$ ). In regard to other tissues examined, a precise allocation of $\mathrm{Rfcl}$ immunoreactivity to subcellular compartments was not possible.

\section{Discussion}

Reduced folate coenzymes like N5-methyltetrahydrofolate are essential cofactors vitally required for cell growth and differentiation. Generally, uptake of folates into mammalian cells can be mediated by three transport systems: the Reduced folate carrier (Rfcl), ${ }^{3}$ the family of folate receptors (FR), ${ }^{3}$ and the proton-coupled folate transporter (PCFT/ SLC46A1). ${ }^{27}$

With exception of kidney normal tissues express low to negligible levels of FR. ${ }^{28}$ Interestingly, porcine FR protein has been recently detected in hepatocellular plasma membranes as well as in kidney but not jejunal brush-border membranes. ${ }^{29}$ However, in man and rodent FR is absent in both liver and intestine. ${ }^{30}$ Expression of PCFT was found in human (hPCFT) and murine (mPCFT) small intestine, kidney, liver, placenta, retina, and brain. ${ }^{30}$ No information is as yet available on PCFT expression in rat normal tissues. hPCFT/mPCFT and hRFC/mRfc are both localized at the apical brush-border membrane and contribute to folate absorption at acidic $\mathrm{pH}$ though recent data indicate that PCFT represents the main intestinal folate uptake system..$^{30,31}$ However, both transporters are upregulated in small intestine in mice fed a folatedeficient diet. ${ }^{30}$ In rat small intestine, PCFT seems to play a minor role in folate absorption as siRNA to rRfc almost completely abolished folate uptake at $\mathrm{pH} 5.5$ in PCFT-expressing (Halwachs et al., unpublished data) ratderived intestinal epithelial IEC-6 cells. $^{9}$ Moreover, PCFT is generally negligible in systemic delivery of folate at neutral $\mathrm{pH}$ as this carrier only displays optimal transport activity at acidic $\mathrm{pH} .{ }^{32}$ At neutral $\mathrm{pH}, \mathrm{Rfcl}$ is therefore regarded as the predominant route for membrane transport of reduced folates in mammalian tissues. Besides, Rfc1 mediates cellular uptake of antifolate drugs such as methotrexate (MTX). ${ }^{5}$ As the loss of transport function results in MTX tumour cell resistance, ${ }^{5} \mathrm{Rfc1}$ uptake activity represents the major determinant of the clinical efficacy of MTX chemotherapy.

Although gene expression studies demon- strated that human and murine RFC1/Rfcl transcripts are expressed ubiquitously but to different levels in all tissues. ${ }^{5,13}$ Rfcl protein expression was only assessed in selected murine tissues such as small intestine. ${ }^{21}$ Furthermore, there is only limited data on the subcellular distribution of this carrier protein. With regard to rat, a common animal model for man, no detailed information on Rfcl gene expression and protein levels is as yet available. In order to better understand the role of Rfcl in folate homeostasis and MTX cytotoxicity, we systematically examined Rfcl gene and protein expression as well as subcellular carrier localization in selected normal tissues from rat.

Our results demonstrate that Rfc1 mRNA is expressed in all selected rat tissues but the Rfc1 transcript level varies from tissue to tissue. In line with results regarding human ${ }^{33}$ and murine ${ }^{34} \mathrm{Rfcl}$ gene expression, the highest mRNA levels were determined in colon, kidney, brain, and lymphatic organs including spleen and thymus. In contrast to human $\mathrm{RFCl},{ }^{33}$ rRfc1 gene expression in liver and peripheral blood leucocytes was less pronounced while carrier expression for other tissues examined were in the same range as shown for human or murine Rfc1.33,34 Differences in hepacellular or leucocyte Rfc1 gene expression may reflect different levels of transcription factors due to species-specific alternate signalling pathways. ${ }^{5}$ Additionally, in tissues demonstrating high rRfcl transcript levels including kidney or lymphatic organs the mRNA variant Rfc2 resulting from alternative splicing ${ }^{7,20}$ could also be detected. However, it is unlikely that this alternative transcript are directly involved in membrane transport of folate derivates as the resulting protein is retained in the cytosol and subsequently degraded as shown for Rfc2 from kidney. ${ }^{35}$

Previous studies indicate that different transcription factors including members of the Sp family or usage of alternate promoters/noncoding exons play an important role in the tissue-specific Rfc1 expression and function. ${ }^{5}$ As organs exhibiting high cell proliferation including bone marrow or testes showed strong Rfcl gene expression while in differentiated tissues such as cardiac muscle cells or lung only low Rfcl signals were detected, the specific Rfc1 distribution pattern may reflect different requirements for folates. Accordingly, only low folate levels were observed in lung and skeletal or cardiac muscle cells ${ }^{36}$ suggesting a minor role for Rfc1-mediated transport in these tissues.

In this study, tissue distribution of Rfcl protein was investigated using a newly synthesized rabbit rRfcl antiserum termed ID7 directed against the $\mathrm{C}$-terminus of the carrier protein. Antibody specificity was confirmed in
MDCK II cells stably expressing rRfc1-HA by application of pET-ID7 fusion protein as a specific blocking peptide. Furthermore, our results derived from Western blot and immunocytochemical analyses using Rfcl antiserum demonstrated an approximately 72 $\mathrm{kDa}$ protein localized to the plasma membrane of MDCK-rRfc1-HA cells similar to previous findings by Kneuer et al., ${ }^{8}$ who used a specific anti-HA antibody for rRfc1 detection. Similarly, a $\sim 70 \mathrm{kDa}$ protein was also detected in various human tumour cell lines using hRFC antiserum. $^{37}$

Our results argued for subcellular localization of rRfcl at the apical brush-border membrane of jejunum and colon. Importance of these results are illustrated by the fact that mammalian cells cannot synthesize folates de novo necessitates carrier-mediated internalization of dietary folates across the apical intestinal membrane including Rfcl in order to maintain folate homeostasis and thereby ensure cell growth and survival. ${ }^{3}$ The critical role of Rfc1 in folate absorption is supported by the fact that dietary folate deficiency leads to a marked upregulation in Rfcl expression and intestinal folate uptake. ${ }^{34,38}$ Moreover, Rfc1 expression correlates with the content of dietary or bacterial synthesized folate in duodenum and colon, respectively. Besides, prominent expression of Rfc1 may determine antitumour activity of antifolate drugs including MTX and contribute to common intestinal cytotoxicity after oral MTX application associated with villos atrophy. ${ }^{39}$

In contrast to intestine, Rfc1 was localized to the basolateral membrane of renal tubular epithelial cells. Similar results were obtained for murine Rfc1. ${ }^{21}$ The observed strong carrier expression may provide an indication of the involvement of $\mathrm{Rfcl}$ in folate reabsorption from the glomerular filtrate probably in concert with folate receptors found in the apical tubular membrane. ${ }^{3,28}$ This hypothesis is corroborated by previous findings showing a significant ethanol-induced decrease in renal folate uptake as a result of reduced folate receptor as well as Rfc1 expression in the apical and basolateral membrane, respectively. ${ }^{40}$ Likewise, MTX is primarily eliminated by renal excretion $^{4}$ and MTX chemotherapy is often related to renal dysfunction resulting in delayed drug elimination and enhanced MTX toxicity. ${ }^{41}$ Precipitation of MTX and its metabolites in the renal tubules represents a major cause of MTX nephrotoxicity. ${ }^{41}$ As previous studies demonstrated a significant increase in MTX cytotoxicity in Rfc1-expressing renal MDCK cells compared to Rfc1-lacking wild-type cells, ${ }^{8}$ a direct involvement of Rfcl in MTX nephrotoxocity is also very likely.

Rfcl was predominantly apparent at the sinusoidal membrane of periportal hepato- 
cytes. The liver represents the main storage side for folate and provides redistribution of reduced folate cofactors to peripheral tissues via the enterohepatic cycle. ${ }^{42}$ As important metabolic liver functions take place in the periportal zone of the liver lobule, Rfc1-mediated internalization and subsequent formation of folate polyglutamates as the intracellular storage form is very likely. Formation of MTX polyglutamates is also responsible for druginduced hepatotoxicity. In line with the observed periportal carrier localization, MTX therapy resulted in periportal liver fibrosis. ${ }^{43}$

In accordance to Rfcl gene expression, prominent apical staining of rRfcl protein was observed in the apical membrane of choroid plexus (CP) epithelial cells composing the blood-CSF-barrier (BCB). This expression pattern reflects the essential role of Rfc1 in cerebral folate homeostasis as Rfcl mediates secretion of reduced folates into CSF resulting in four times the plasma folate concentration. ${ }^{44}$ Clinical significance of Rfcl expression in BCB is illustrated by previous studies that have linked folate deficiency to neurologic disorders such as depression as reduced levels of a 5-hydroxytryptamine metabolite were restored to normal in individuals after folate supplementation. ${ }^{45}$ Conversely, MTX is eliminated from CSF into blood via uptake through Rfcl and Mrp-mediated extrusion of the drug. ${ }^{44}$ Neurotoxicity is a common complication in patients who receive systemic or intrathecal MTX therapy resulting in neurologic disorders such as seizures. ${ }^{4}$ This may be due to abnormal MTX efflux across the BCB as formerly suggested for patients with central nervous system leukemia. ${ }^{46}$

In conclusion, our results show that although the rRfcl is expressed ubiquitously, the intensity of its expression varies strongly. The prevalent tissue distribution of the carrier supports the pivotal role of Rfcl uptake activity in folate homeostasis reflecting strong folate requirements of high proliferating tissues or specialized tissue functions as shown for various tissues involving reduced folate coenzymes. As a consequence, impairment of Rfcl-mediated folate transport results in disruption of physiological folate homeostasis and thereby enhances the existing widespread latent folate deficiency, due to an inadequate dietary folate intake. ${ }^{47-49}$ Folate deficiency finally increases the risk of neural tube defects in neonates, cardiovascular diseases, ${ }^{2}$ and cancer. ${ }^{50,51}$

\section{References}

1. Birn H. The kidney in vitamin B12 and folate homeostasis: characterization of receptors for tubular uptake of vitamins and carrier proteins. Am J Physiol Renal Physiol 2006;291:F22-36.

2. Ganapathy V, Smith SB, Prasad PD. SLC19: the folate/thiamine transporter family. Pflügers Arch 2004;447:641-6.

3. Sirotnak FM, Tolner B. Carrier-mediated membrane transport of folates in mammalian cells. Annu Rev Nutr 1999;19:91122.

4. Josting A, Diehl V, Engert A. Methotrexat: Pharmakologie, Toxizität und Rescuemassnahmen bei hochdosierter Behandlung. Onkologe 1998;4:974-85.

5. Matherly LH, Goldman ID. Membrane transport of folates. Vitam Horm 2003;66:403-56.

6. Gromnica-Ihle E. Pharmacotherapy of rheumatoid arthritis. Z Rheumatol 2002;61:35-8.

7. Honscha W, Dötsch KU, Thomsen N, Petzinger E. Cloning and functional characterization of the bile acid-sensitive methotrexate carrier from rat liver cells. Hepatology 2000;31:1296-304.

8. Kneuer C, Honscha KU, Honscha W. Rat reduced-folate carrier-1 is localized basolaterally in MDCK kidney epithelial cells and contributes to the secretory transport of methotrexate and fluoresceinated methotrexate. Cell Tissue Res 2005;320:517-24.

9. Balamurugan K, Said HM. Role of reduced folate carrier in intestinal folate uptake. Am J Physiol Cell Physiol 2006;291:C18993.

10. Moscow JA, Gong M, He R, Sgagias MK, Dixon KH, Anzick SL, et al. Isolation of a gene encoding a human reduced folate carrier (RFC1) and analysis of its expression in transport-deficient, methotrexateresistant human breast cancer cells. Cancer Res 1995;55:3790-4.

11. Dixon KH, Lampher BC, Chiu J, Kelley K, Cowan $\mathrm{KH}$. A novel cDNA restores reduced folate carrier activity and methotrexate sensitivity to transport deficient cells. J Biol Chem 1994;269:17-20.

12. Williams FM, Murray RC, Underhill TM, Flintoff WF. Isolation of a hamster cDNA clone coding for a function involved in methotrexate uptake. J Biol Chem 1994; 269:5810-6.

13. Ferguson PL, Flintoff WF. Topological and functional analysis of the human reduced folate carrier by hemagglutinin epitope insertion. J Biol Chem 1999;274:16269-78.

14. Honscha W, Petzinger E. Characterization of the bile acid sensitive methotrexate carrier of rat liver cells. Naunyn Schmiedebergs Arch Pharmacol 1999;359: 411-9.

15. Sierra EE, Goldman ID. Recent advances in the understanding of the mechanism of membrane transport of folates and antifolates. Semin Oncol 1999;26:11-23.

16. Kneuer C, Honscha W. The H(+)-dependent reduced folate carrier 1 of humans and the sodium-dependent methotrexate carrier-1 of the rat are orthologs. FEBS Lett 2004;566:83-6.

17. Horne DW. Na+ and $\mathrm{pH}$ dependence of 5methyltetrahydrofolic acid and methotrexate transport in freshly isolated hepatocytes. Biochim Biophys Acta 1990;1023:4755.

18. Gewirtz DA, White JC, Randolph JK, Goldman ID. Transport, binding, and polyglutamation of methotrexate in freshly isolated rat hepatocytes. Cancer Res 1980; 40:573-8.

19. Rajgopal A, Sierra EE, Zhao R, Goldman ID. Expression of the reduced folate carrier SLC19A1 in IEC-6 cells results in two distinct transport activities. Am J Physiol Cell Physiol 2001;281:C1579-86.

20. Kneuer C, Schrader S, Honscha W. Alternative transcripts of rat slc19a1: cloning, genomic organisation, tissue specific promoters and alternative splicing. DNA Seq 2005; 16:1-6.

21. Wang Y, Zhao R, Russell RG, Goldman ID. Localization of the murine reduced folate carrier as assessed by immunohistochemical analysis. Biochim Biophys Acta 2001; 1513:49-54.

22. Chancy CD, Kekuda R, Huang W, Prasad PD, Kuhnel JM, Sirotnak FM, et al. Expression and differential polarization of the reduced-folate transporter- 1 and the folate receptor alpha in mammalian retinal pigment epithelium. J Biol Chem 2000;275:20676-84.

23. Villanueva JA, Devlin AM, Halsted CH. Reduced folate carrier: tissue distribution and effects of chronic ethanol intake in the micropig. Alcohol Clin Exp Res 2001;25:415-20.

24. Jameson BA, Wolf $H$. The antigenic index: a novel algorithm for predicting antigenic determinants. Comput Appl Biosci 1988;4:181-6.

25. Halwachs S, Kneuer C, Honscha W. Downregulation of the reduced folate carrier transport activity by phenobarbitaltype cytochrome P450 inducers and protein kinase $\mathrm{C}$ activators. Biochem Biophys Acta 2007;1768:1671-9.

26. Laemmli UK. Cleavage of structural proteins during the assembly of the head of bacteriophage T4. Nature 1970;227:680-5.

27. Qiu A, Jansen M, Sakaris A, Min SH, Chattopadhyay S, Tsai E et al, Identification of an intestinal folate transporter and the molecular basis for hereditary folate malabsorption. Cell 
2006;127:917-28.

28. Parker N, Turk MJ, Westrick E, Lewis JD, Low PS, Leamon CP. Folate receptor expression in carcinomas and normal tissues determined by a quantitative radioligand binding assay. Anal Biochem 2005;338:284-93.

29. Villanueva J, Ling EH, Chandler CJ, Halsted $\mathrm{CH}$. Membrane and tissue distribution of folate binding protein in pig. Am J Physiol 1998;275:R1503-10.

30. Zhao R, Matherly LH, Goldman ID. Membrane transporters and folate homeostasis: intestinal absorption and transport into systemic compartments and tissues. Expert Rev Mol Med 2009; 11:e4.

31. Qiu A, Min SH, Jansen M, Malhotra U, Tsai E, Cabelof DC, et al. Rodent intestinal folate transporters (SLC46A1): secondary structure, functional properties, and response to dietary folate restriction. Am J Physiol Cell Physiol 2007;293:C1669-78.

32. Nakai Y, Inoue K, Abe N, Hatakeyama M, Ohta KY, Otagiri M, et al, Functional characterization of human proton-coupled folate transporter/heme carrier protein 1 heterologously expressed in mammalian cells as a folate transporter. J Pharmacol Exp Ther 2007; 322:469-76.

33. Whetstine JR, Flatley RM, Matherly LH. The human reduced folate carrier gene is ubiquitously and differentially expressed in normal human tissues: identification of seven non-coding exons and characterization of a novel promoter. Biochem $\mathrm{J}$ 2002;367:629-40.

34. Liu M, Ge Y, Cabelof DC, Aboukameel A, Heydari AR, Mohammad R, et al. Structure and regulation of the murine reduced folate carrier gene: identification of 4 noncoding exons and promoters and regula- tion by dietary folates. J Biol Chem 2005;280:5588-97.

35. Schrader S, Kneuer C, Said HM, Honscha W. Alternative transcripts of rat slc19al: defective sorting and inefficient expression of alternative splicing products--an addendum. DNA Seq 2006;17:83-6.

36. Clifford AJ, Heid MK, Müller HG, Bills ND. Tissue distribution and prediction of total body folate of rats. J Nutr 1990;120:1633-9.

37. Trippett TM, Garcia S, Manova K, Mody R, Cohen-Gould L, Flintoff W, et al. Localization of a human reduced folate carrier protein in the mitochondrial as well as the cell membrane of leukemia cells. Cancer Res 2001;61:1941-7.

38. Said HM, Chatterjee N, Haq RU, Subramanian VS, Ortiz A, Matherly LH, et al. Adaptive regulation of intestinal folate uptake: effect of dietary folate deficiency. Am J Physiol Cell Physiol 2000;279:C188995.

39. Pinkerton CR. Is folate absorption impaired by high dose methotrexate? Br J Cancer 1983;47: 303-5.

40. Hamid A, Kaur J. Decreased expression of transporters reduces folate uptake across renal absorptive surfaces in experimental alcoholism.J Membr Biol 2007;220:69-77.

41. Widemann BC, Adamson PC. Understanding and managing methotrexate nephrotoxicity. Oncologist 2006;11:694-703.

42. Lucock M. Folic acid: nutritional biochemistry, molecular biology, and role in disease processes. Mol Genet Metab 2000;71:12138.

43. Lemann M, Zenjari T, Bouhnik Y, Cosnes J, Mesnard B, Rambaud JC, et al. Methotrexate in Crohn's disease: longterm efficacy and toxicity. Am J
Gastroenterol 2000;95:1730-4.

44. Spector R, Johanson CE. Vectorial ligand transport through mammalian choroid plexus. Pharm Res 2010;27:2054-62.

45. Botez MI, Young SN, Bachevalier J, Gauthier S. Effect of folic acid and vitamin B12 deficiencies on 5-hydroxyindoleacetic acid in human cerebrospinal fluid. Ann Neurol 1982;12:479-84.

46. Ettinger LJ, Chervinsky DS, Freeman AI, Creaven PJ. Pharmacokinetics of methotrexate following intravenous and intraventricular administration in acute lymphocytic leukemia and non-Hodgkin's lymphoma. Cancer 1982;50:1676-82.

47. Beitz R, Mensink GB, Fischer B, Thamm M. Vitamins - dietary intake and intake from dietary supplements in Germany. Eur J Clin Nutr 2002;56:539-45.

48. García-Casal, MN, Osorio C, Landaeta M, Leets I, Matus P, Fazzino F, et al. High prevalence of folic acid and vitamin B12 deficiencies in infants, children, adolescents and pregnant women in Venezuela. Eur J Clin Nutr 2005;59:1064-70.

49. Oakley GP Jr. Global prevention of all folic acid-preventable spina bifida and anencephaly by 2010 . Community Genetics 2002;5:70-7.

50. Gatof D, Ahnen D. Primary prevention of colorectal cancer: diet and drugs. Gastroenterol Clin North Am 2002;31:587623.

51. Stolzenberg-Solomon RZ, Chang SC, Leitzmann MF, Johnson KA, Johnson C, Buys SS, et al. Folate intake, alcohol use, and postmenopausal breast cancer risk in the Prostate, Lung, Colorectal, and Ovarian Cancer Screening Trial. Am J Clin Nutr 2006;83:895-904. 